\title{
OS PAPÉIS DESEMPENHADOS POR GOVERNO, UNIVERSIDADE, EMPRESA E INSTITUIÇÃO CIENTÍFICA E TECNOLÓGICA: UMA ANÁLISE DE MUNICÍPIOS DE SÃO PAULO E RIO DE JANEIRO À LUZ DA TIPOLOGIA DE DISTRITOS INDUSTRIAIS DE ANN MARKUSEN
}

\author{
Renato Santiago Quintal \\ Pagadoria de Pessoal da Marinha (PAPEM), Mestre em Ciências Contábeis (UERJ) \\ E-mail: rsantiago79@ hotmail.com; http://lattes.cnpq.br/4729836017574731
}

\author{
Branca Regina Cantisano dos Santos e Silva Riscado Terra \\ Professora do Programa de Pós-graduação em Ciências Contábeis (PPGCC-UERJ), Doutora \\ em Engenharia de Produção (COPPE-UFRJ) \\ E-mail: brancaterra@gmail.com; http://lattes.cnpq.br/2248903075480185
}

\author{
Marcos dos Santos \\ Centro de Análise de Sistemas Navais (CASNAV), Mestre em Engenharia de Produção \\ (COPPE-UFRJ) \\ E-mail: marcossantos@ casnav.mar.mil.br; http://lattes.cnpq.br/5534398558592175
}

\begin{abstract}
Resumo
O Sistema Nacional de Inovação contempla todos os segmentos do arcabouço econômico e institucional que influenciam os processos de aprendizado, busca e exploração de inovações. Não somente as entidades orientadas ao apoio das atividades de pesquisa e desenvolvimento, mas também a malha de relacionamento entre usuários e fornecedores, relações trabalhistas, arcabouço jurídico e políticas públicas. O presente artigo assume como tema a análise dos papéis desempenhados pelos atores governo, universidade, empresa e instituição científica tecnológica em municípios localizados em território paulista e fluminense. No estudo em tela, vislumbram-se os seguintes problemas de pesquisa: Como estão dispostos os atores nos municípios analisados? As características demográficas e socioeconômicas daqueles municípios propiciam o desenvolvimento de ambientes de inovação? Quais são as contribuições fornecidas pelos atores envolvidos ao desenvolvimento de ambientes de inovação nos municípios analisados? Como poderiam ser classificados os distritos industriais nos quais estão situadas as unidades de análise da pesquisa? No que tange à metodologia, a presente pesquisa pode ser classificada como qualitativa e quantitativa, exploratória, bibliográfica, documental, pesquisa de campo e estudos de casos. Observa-se que governo, universidade e empresa assumem disposições distintas em cada um dos municípios em estudo. Adicionalmente, as características atinentes aos índices de Gini e de desenvolvimento humano; ao ranking de empregos; e à representatividade das instituições científicas e tecnológicas instaladas em cada um dos municípios contribuem ou não para a conformação de ambientes de inovação e polos tecnológicos naquelas localidades. A característica comum aos três municípios é o fato de representarem exemplos de distritos industriais suportados pelo Estado, de acordo com a tipologia apresentada por Markusen. Este estudo apresenta limitações associadas ao fato de o resultado da pesquisa estar adstrito exclusivamente aos três casos estudados, sendo impossível a sua generalização.
\end{abstract}

Palavras-chave: Sistema nacional de inovação; ambientes de inovação; municípios brasileiros; distritos industriais.

\footnotetext{
Abstract

The National Innovation System includes all segments of the institutional and economic framework that influence the processes of learning, searching and exploring innovations. Not only the entities targeted support of research and development, but also the
} 
fabric of relationships between users and suppliers, labor relations, legal framework and policies. This article takes as its theme the analysis of the roles played by actors government, university, business and scientific institution technological municipalities in Rio de Janeiro and Sao Paulo State. In the study on the screen, envision the following research problems: How willing are the actors in the municipalities analyzed? The demographic and socioeconomic characteristics of those counties favor the development of innovation environments? What are the contributions made by stakeholders to the development of innovation environments in the municipalities analyzed? How could be classified industrial districts in which are situated the units of analysis of the research? Regarding methodology, this research can be classified as qualitative and quantitative, exploratory, bibliographical, documentary, field research and case studies. It is observed that government, universities and companies take different provisions in each of the counties in the study. Additionally, the characteristics associated with the Gini index and human development ranking of the jobs, and the representativeness of the scientific and technological institutions installed in each of the municipalities or not contribute to the shaping of environments for innovation and technological centers in those locations. The characteristic common to the three municipalities is the fact they represent examples of industrial districts state-centered, according to the typology by Markusen. This study has limitations related to the fact that the result of the survey is attached exclusively to the three cases studied, and it is impossible to generalize.

Keywords: National innovation system; innovation environments; municipalities; industrial districts.

\section{INTRODUÇÃO}

O Estado emergente necessita tomar para si a atribuição de indutor do progresso e estimular a parceria entre a esfera pública, as instituições de ensino superior e o segmento empresarial, sustentáculo de todo projeto nacional (AMARAL, 2011). Esse ente reúne ainda competências e ofícios que o posicionam como o primordial elemento no processo de criação de políticas e de fomento de inovações, em sua área territorial e nas cercanias regional e mundial, como se observa na maior parte das nações emergentes e industrializadas (CRUZ JÚNIOR, 2011).

O Sistema Nacional de Inovação (SNI) contempla todos os segmentos do arcabouço econômico e institucional que influenciam os processos de aprendizado, busca e exploração de inovações. Não somente as entidades orientadas ao apoio das atividades de pesquisa e desenvolvimento, mas também a malha de relacionamento entre usuários e fornecedores, relações trabalhistas, arcabouço jurídico e políticas públicas (LUNDVALL, 1992).

A associação da ideia de redes formais e informais de inovação ao processo de inovação e às propostas de políticas de inovação foi idealizada a partir da contribuição da Diretoria de Ciência, Tecnologia e Indústria (DCTI) da Organização para Cooperação e Desenvolvimento Econômico (OCDE). Foi formado um grupo para essa finalidade composto por personalidades como: François Chesnais - membro da DCTI; Christopher Freeman e Keith Pavitt (ex-integrantes da DCTI); Richard Nelson, entre outros. A atuação desse grupo de trabalho resultou na produção de documento - "Transformação técnica e política econômica" - que significou um marco, por representar o primeiro documento de política de inovação confeccionado por um organismo internacional a enfrentar os argumentos da macroeconomia tradicional acerca da crise da década de 1970 e a enfatizar a contribuição das novas tecnologias para a superação daquele momento. Os trabalhos daquele grupo já apontavam para a natureza sistêmica da inovação. Foi no início da década de 1980 que os países desenvolvidos tomaram consciência de que as decisões e as estratégias tecnológicas estão diretamente associadas aos setores financeiros, aos sistemas educacionais e à 
organização do trabalho, indicando uma definição de "Sistema Nacional de Inovação" (CASSIOLATO e LASTRES, 2005).

O presente artigo assume como tema a análise dos papéis desempenhados pelos atores governo, universidade, empresa e instituição científica tecnológica em municípios localizados em território paulista e fluminense.

No estudo em tela, vislumbram-se os seguintes problemas de pesquisa: Como estão dispostos os atores nos municípios analisados? As características demográficas e socioeconômicas daqueles municípios propiciam o desenvolvimento de ambientes de inovação? Quais são as contribuições fornecidas pelos atores envolvidos ao desenvolvimento de ambientes de inovação nos municípios analisados?

Desse modo, o objetivo geral do artigo é analisar e criticar os papéis desempenhados pelos atores governo, universidade, empresa. Os objetivos específicos são: 1) identificar e examinar a disposição dos atores supracitados nos municípios analisados; 2) verificar se características demográficas e socioeconômicas daqueles municípios propiciam o desenvolvimento de ambientes de inovação; e 3) identificar e examinar as contribuições dos atores supracitados ao desenvolvimento de ambientes de inovação nos municípios analisados.

No que tange à metodologia, a presente pesquisa pode ser classificada como qualitativa e quantitativa, exploratória, bibliográfica, documental, pesquisa de campo e estudos de casos. Os estudos de casos contemplam os seguintes municípios como unidades de análise: 1) São José dos Campos, com localização no estado de São Paulo, e município-sede do Instituto de Fomento e Coordenação Industrial (IFI); 2) Campinas, igualmente localizado no estado de São Paulo, e sede do Centro de Pesquisa e Desenvolvimento em Telecomunicações (CPqD); 3) Arraial do Cabo, com localização no estado do Rio de Janeiro, e sede do Instituto de Estudos do Mar Almirante Paulo Moreira (IEAPM).

Empreender o estudo em pauta poderá contribuir para o avanço do conhecimento já existente sobre o tema. Adicionalmente, a temática encontra-se aderente aos estudos desenvolvidos no grupo de pesquisa "inovação e sociedade", cadastrado no Diretório dos Grupos de Pesquisa no Brasil, administrado pelo CNPq. Convém destacar que o resultado da pesquisa está adstrito às três unidades de análise, sendo impossível a sua generalização.

O presente artigo é composto de introdução; fundamentação teórica; método de pesquisa; análise dos resultados; conclusões; e referências.

\section{FUNDAMENTAÇÃO TEÓRICA}

A fundamentação teórica do artigo é composta por três subseções, a saber: sistemas de inovação; ambiente de inovação; e novos distritos industriais.

\subsection{Sistemas de inovação}

O embaraço maior vislumbrado pelos países por ocasião do investimento em seus sistemas de inovação corresponde à incerteza intrínseca ao desempenho dos sistemas e respectivos agentes, especialmente quando não há amadurecimento e integração entre os componentes do sistema (CRUZ JÚNIOR, 2011). O sistema local de inovação está relacionado ao exame de uma região pertencente a um sistema nacional de inovação e as circunstâncias que a permeiam. Em hipótese alguma, a ingerência do sistema nacional sobre o sistema regional de inovação poderá ser olvidada (TERRA, 2007).

Deve-se examinar o sistema nacional de inovação de países de industrialização recente sob a ótica de dois arcabouços analíticos: o contexto tecnológico amplo e o contexto institucional (KIM, 1997). O contexto tecnológico amplo demanda que as organizações empresariais das nações desenvolvidas sofram evolução ao longo do percurso tecnológico

formado a partir de três patamares: fluido, transacional e específico. No primeiro, observa-se uma maior circulação de informações entre os departamentos da empresa, contribuindo para que ocorra a inovação tecnológica do produto. O segundo patamar é caracterizado pela redução de inovações no produto, acompanhada de um aumento de inovações no processo. 
Por fim, o último patamar - o específico - pode ser caracterizado pelo enfoque dado pela organização ao incremento da produção e à viabilidade comercial do produto. Nesse patamar, caracterizado pela consolidação de posição no mercado e pela adoção de gestão austera, observa-se a diminuição da comunicação, verificada nos patamares anteriores, e a redução da capacidade de inovação tecnológica (UTTERBACK, 1994).

O contexto institucional abarca distintos agentes econômicos e os demais componentes que atuam no aprendizado tecnológico no sistema nacional de inovação (KIM, 1997; LUNDVALL, 1992; NELSON, 1993). Dentre o rol de agentes e componentes, podem ser elencados os entes governamentais e as políticas por eles conduzidas, as ações dos arranjos industriais, um sistema educacional disponível e qualificado, o suporte às atividades de pesquisa e desenvolvimento (P\&D), a essência mutável dos elementos socioculturais, o relacionamento entre compradores e fornecedores na praça internacional e local, o montante investido em $\mathrm{P} \& \mathrm{D}$, a gestão empresarial e o inter-relacionamento entre os atores e os componentes acima citados. O exame do sistema nacional de inovação necessita perquirir a efetividade dos seus componentes e como eles interagem ao longo da trajetória tecnológica (KIM, 2005, p. 450).

De acordo com documentos da Comissão Européia, órgão executivo da União Européia, os componentes do sistema regional de inovação podem reunidos em contextos, de acordo com a ação desempenhada no processo de inovação (EUROPEAN COMMISSION 1999a, 1999b):

- os bens e serviços são gerados no contexto produtivo, que é composto pelas organizações empresarias e pelas entidades correspondentes, tais como órgãos de registro e representativos;

- $\quad$ os conhecimentos científicos são produzidos no contexto científico, que é formado pelas universidades e pelas instituições públicas de pesquisa. Nessa circunstância, são realizados exames envolvendo atividades, investimentos, indivíduos, propriedade intelectual e coordenação de esforços em âmbito nacional;

- as tecnologias são desenvolvidas no contexto tecnológico, organizado a partir de institutos de ciência e tecnologia, parques tecnológicos, laboratórios, indústrias de máquinas e equipamentos e empresas de engenharia e de serviços sofisticados;

- $\quad$ os recursos financeiros indispensáveis a operações dos diversos contextos inserem-se no cenário financeiro, que é formado pelo sistema bancário, clubes de investimento e entidades governamentais de fomento à inovação;

- $\quad$ o delineamento do suporte necessário ao progresso é realizado no contexto logístico ou operacional. Nesse âmbito, é verificada a disponibilidade de infraestrutura rodoviária, ferroviária, portuária, aeroportuária, hospitalar, laboratorial, escolar e de comunicações;

- $\quad$ os óbices às ações indispensáveis à estruturação do processo de desenvolvimento e o exame das medidas voltadas para regulação e estímulo à inovação tecnológica são tratadas no contexto legal. É nesse ambiente que estão previstas as ferramentas legais que assegurarão a manutenção do desenvolvimento tecnológico regional.

Essa abordagem adquiriu novos contornos com a inserção dos contextos social e ambiental, trazidos à baila por um grupo de autores (TERRA et al., 2000; TERRA; BARROS; SEIDL, 2001a, 2001b). Esses dois novos contextos vêm adquirindo grande relevância, especialmente na conjuntura dos países em desenvolvimento. A responsabilidade social das organizações empresariais e as figuras dos "empreendedores sociais ou cívicos" se fazem presente no contexto social. Por fim, todo e qualquer emprego de tecnologia limpa, voltado para a geração de inovação, bem como os impactos nele provocados, estão inseridos no contexto ambiental (TERRA, 2007, p. 7).

\subsection{Ambiente de inovação}

O conceito de ambiente de inovação está associado a uma perspectiva distinta no que tange as possibilidades de edificação da prática de inovação, com o objetivo de ajustar 
elementos tecnológicos, econômicos e sociais de modo diferenciado e aberto, apartado do modelo que associa inovação tecnológica unicamente ao setor produtivo (MACIEL, 2001). O ambiente de inovação refere-se ao agregado de fatores de ordem política, econômica, social e cultural que fomentam ou embaraçam a inovação (MACIEL e BAUMGARTEN, 2005). Adicionalmente, os ambientes de inovação consideram componentes oriundos do legado cultural e da criatividade característica de um grupo social, que, por tradição, não são legitimados como partes constituintes da inovação (ANDRADE, 2006).

Parques Tecnológicos correspondem a ambientes de inovação. São ferramentas empregadas em nações desenvolvidas e em desenvolvimento a fim de tornarem as suas economias regionais e nacionais mais dinâmicas, por meio da agregação de teor de conhecimento; outrossim, são estruturas que tem o objetivo de converter conhecimento em riqueza. Desse modo, esses países tornam-se mais competitivos no plano internacional, criam empregos qualificados, recolhem impostos e promovem o bem-estar social. É característico que parques tecnológicos estejam situados nas proximidades de universidades e centros de pesquisa, polos produtores de conhecimento e formadores de recursos humanos qualificados. Trata-se de uma aproximação que produz sinergia e oportunidade. No estado de São Paulo, o Sistema Paulista de Parques Tecnológicos (SPPT) foi vislumbrado com o objetivo de sistematizar uma política que fomentasse o surgimento e o estabelecimento de conexões entre os parques tecnológicos no estado. Fez-se necessária a articulação entre o poder público - e os seus distintos níveis -, a academia e o setor privado, notadamente representado pelos segmentos empresarial e imobiliário (STEINER, CASSIM e ROBAZZI, 2008).

Em C,T\&I, há uma gama de definições que caracterizam a reunião de empreendimentos de base tecnológica. A concepção de polo tecnológico é empregada no sentido de delinear uma região onde exista uma reunião maior de atividades tecnológicas do que em outras localidades. No estado de São Paulo, as cidades de Campinas, São José dos Campos e São Carlos são exemplos típicos de polos tecnológicos. Outra conceituação desenvolvida recentemente está relacionada aos arranjos produtivos locais, que são objeto de interesse da Secretaria de Desenvolvimento, do Serviço Brasileiro de Apoio às Micro e Pequenas Empresas (SEBRAE) e da Federação das Indústrias do Estado de São Paulo (FIESP), com o propósito de estimular a competitividade e a sustentabilidade de micro e pequenas empresas, não estando a inovação tecnológica no cerne principal dessa abordagem. Por fim, convém elencar o entendimento acerca de incubadoras de base tecnológica: são organizações que almejam especificamente acolher e fomentar micro e pequenas empresas, a fim de tornar viável seu avanço inicial e temporário, além de igualmente tornar viável a sua criação (STEINER, CASSIM e ROBAZZI, 2008).

\subsection{Novos distritos industriais}

A pesquisadora Ann Markusen (1995) sistematizou o conhecimento envolvendo nos distritos industriais. Essas estruturas econômicas correspondem a áreas espacialmente delimitadas, com uma nova orientação de atividade econômica de exportação e especialização definida, seja ela relacionada à base de recursos naturais, ou a determinados tipos de industriais ou serviços. Adicionalmente, a definição de um distrito industrial deve contemplar essencialmente as seguintes condições, a saber: obtenção, na região, de taxas de crescimento na média ou acima da média do verificado para o conjunto das áreas pesquisadas; capacidade local de se evitar falências e perdas de postos de trabalho decorrentes dos efeitos das oscilações de curto e médio prazo, tanto dos ciclos de negócio, quanto dos gastos públicos; oferta de bons empregos, a contenção das tendências à segmentação salarial e a prevenção de excessiva concentração da renda e da propriedade; livre organização dos trabalhadores e a sua participação nos processos decisórios das empresas; e incentivo à participação e à contestação política em âmbito regional. O quadro 1 abaixo apresenta cinco espaços industriais distintos e as suas respectivas características. 


\begin{tabular}{|c|c|}
\hline Tipologia & Características \\
\hline $\begin{array}{l}\text { Marshalliano } \\
\text { tradicional }\end{array}$ & $\begin{array}{l}\text { Estrutura econômica baseada em pequenas firmas com origem, propriedade e decisões sobre } \\
\text { investimentos e produção de base local. Economias de escala são relevantes, o que limita o } \\
\text { tamanho do negócio. Substancial teia de transações intradistrital normalmente favorece } \\
\text { contratos e compromissos de longo prazo. O distrito é visto como uma comunidade } \\
\text { relativamente estável, o que permite o desenvolvimento de uma identidade cultural local e } \\
\text { de uma capacitação industrial compartilhada. Ponto comum ao modelo marshalliano } \\
\text { variedade italiana é o fato de que as firmas - em geral com a ajuda dos governos locais e de } \\
\text { associações de negócios - articulam-se de forma consciente para resolver problemas de } \\
\text { natureza cíclica ou de sobrecapacidade e para responder às novas demandas por } \\
\text { flexibilidade. }\end{array}$ \\
\hline $\begin{array}{l}\text { Marshalliano } \\
\text { variedade } \\
\text { italiana }\end{array}$ & $\begin{array}{l}\text { Alto nível de intercâmbio de pessoal entre consumidores intermediários e fornecedores, } \\
\text { assim como cooperação entre consumidores intermediários e fornecedores, assim como } \\
\text { cooperação entre competidores visando a estabilização de seus mercados e o } \\
\text { compartilhamento de riscos e de inovações. Governos locais ou regionais tendem a } \\
\text { desempenhar um papel central da regulação e na promoção das principais indústrias. A } \\
\text { orientação geral dos seus processos decisórios tem sido muito permeável ao papel } \\
\text { proeminente dos sindicatos, e inclui a garantia do decidido apoio às empresas locais, em } \\
\text { geral nos momentos de baixa dos seus mercados. }\end{array}$ \\
\hline Centro-Radial & $\begin{array}{l}\text { Articulação em torno de uma ou várias grandes corporações pertencente(s) a uma ou a } \\
\text { algumas poucas indústrias. Correspondem a regiões onde certo número de empresas ou de } \\
\text { unidades industriais mais importantes atua como firmas-chave ou eixos da economia } \\
\text { regional, congregando em torno de si fornecedores e outras atividades correlatas. O } \\
\text { dinamismo das economias regionais com esse formato associa-se à posição das suas } \\
\text { principais firmas ou unidades industriais. Substancial comércio interno ao distrito se } \\
\text { organiza em função das suas demandas, com contratos e compromissos de longo prazo. } \\
\text { Destacado apoio das empresas mais importantes à implantação e ao desenvolvimento de } \\
\text { serviços especializados voltados para as suas necessidades específicas. Firmas-chave tratam } \\
\text { com governo local e com o do seu estado em torno de uma agenda restrita, especialmente } \\
\text { relacionados a sua força de trabalho e a sua possibilidade de bem tocar os seus negócios. O } \\
\text { poder de mercado das grandes firmas normalmente implica altos retornos, condição } \\
\text { necessária, ainda que insuficiente para viabilização de mais altos salários. Exemplo } \\
\text { brasileiro: Resende/Porto Real; Região do ABC Paulista. }\end{array}$ \\
\hline $\begin{array}{l}\text { Plataforma } \\
\text { Industrial } \\
\text { Satélite }\end{array}$ & $\begin{array}{l}\text { Constituída por sucursais ou subdivisões de corporações multinacionais, e que tanto pode ter } \\
\text { um caráter high-tech, quanto meramente se basear em filiais atraídas por baixos salários, } \\
\text { baixos impostos e incentivos governamentais. Justificam-se pelo estímulo ao } \\
\text { desenvolvimento de regiões longínquas e pela tentativa de rebaixamento dos custos dos } \\
\text { negócios. Podem variar desde simples rotinas de montagem até pesquisas relativamente } \\
\text { sofisticadas. Total ausência de conexões ou transações no interior do distrito e exclusiva } \\
\text { orientação para a matriz ou para outras subsidiárias da mesma corporação. Altas taxas de } \\
\text { entrada e saída de quadros profissionais nas áreas técnicas ou de gerência, sendo que, } \\
\text { usualmente, apenas a mão de obra voltada para as atividades mais rotineiras é recrutada } \\
\text { localmente. Nesses distritos, não é comum se observar o desenvolvimento de laços culturais } \\
\text { ou novas identidades. Exemplo brasileiro: Zona Franca de Manaus. }\end{array}$ \\
\hline $\begin{array}{l}\text { Suportado } \\
\text { pelo Estado }\end{array}$ & $\begin{array}{l}\text { Capital de Estado, instalações militares, instituições de pesquisa ou alguma empresa estatal } \\
\text { funcionam como âncoras do desenvolvimento econômico regional. É o que se organiza em } \\
\text { torno de alguma entidade pública ou não lucrativa, seja uma base militar, uma universidade, } \\
\text { um centro de pesquisa ou laboratório ligado ao setor bélico, um complexo prisional ou uma } \\
\text { grande concentração de órgãos públicos. A estrutura dos negócios locais é dominada pela } \\
\text { presença dessas instituições antes que pelas empresas privadas ali atuantes. As economias de } \\
\text { escala são relativamente altas nesses complexos. Contratos e compromissos de curto prazo } \\
\text { são usuais, ainda que sujeitos aos azares das mudanças políticas. Favorecem o } \\
\text { desenvolvimento de relações de longo prazo com fornecedores, baseadas em alto grau de } \\
\text { confiança e cooperação. Os mercados de trabalho nessas áreas organizam-se em função das } \\
\text { principais atividades estatais nelas realizadas. Os interesses privados e os governos locais } \\
\text { geralmente trabalham na busca de que a instituição pública-âncora aumente seus } \\
\text { investimentos e gastos na região e/ou não se veja tentada a deixá-la. Distritos industriais } \\
\text { militares vão do mais acirrado conservadorismo ao extremo liberal. Exemplo brasileiro: São } \\
\text { José dos Campos e Campinas. }\end{array}$ \\
\hline
\end{tabular}

Quadro1: Tipologia de distritos industriais sistematizada por Ann Markusen

Fonte: Adaptado de Markusen (1985). 
A próxima seção abordará a metodologia empreendida na presente pesquisa.

\section{MÉTODO DE PESQUISA}

Segundo a natureza dos dados, a presente pesquisa classifica-se como qualitativa. No que se refere ao nível de controle das variáveis, a pesquisa enquadra-se como não experimental (GIL, 2010).

Quanto aos objetivos mais gerais, a presente pesquisa classifica-se como exploratória, uma vez que "tem como propósito proporcionar maior familiaridade com o problema, com vistas a torná-lo mais explícito". Adicionalmente, reveste-se de um planejamento dotado de maior flexibilidade, pois são relevantes as mais diversas facetas referentes ao objeto em estudo (GIL, 2010).

O trabalho igualmente contemplou pesquisas bibliográfica e documental e visitas técnicas. Para a pesquisa bibliográfica, foram consultados materiais impressos e em meio magnético, afetos a "livros, revistas, jornais, teses, dissertações e anais de eventos científicos". Em relação a pesquisa documental, foram acessados documentos provenientes das mais distintas fontes, como "relatos de pesquisa, relatórios e boletins e jornais de empresas, atos jurídicos e compilações estatísticas" (GIL, 2010). Ademais, a pesquisa pode ser classificada como um estudo de caso. Para Yin (2010), o estudo de caso corresponde a um procedimento de natureza empírica que "investiga um fenômeno contemporâneo em profundidade e em seu contexto de vida real", notadamente quando os liames entre fenômeno e contexto não se encontram francamente delineados.

Por fim, foi empreendida pesquisa de campo, estruturada a partir da visita do autor a três instituições científicas e tecnológicas, a saber: Instituto de Fomento e Coordenação Industrial - localizado em São José dos Campos -; Centro de Pesquisa e Desenvolvimento em Telecomunicações - localizado em Campinas -; e Instituto de Estudos do Mar Almirante Paulo Moreira - localizado em Arraial do Cabo. Segundo Rodrigues (2006), a pesquisa de campo contempla a observação dos fatos tal como ocorrem, não havendo a possibilidade de isolar e controlar as variáveis, mas perceber e estudar as relações estabelecidas.

\section{ANÁLISE E DISCUSSÃo}

Esta seção encontra-se dividida em três subseções, a saber: o município de São José dos Campos; o município de Campinas; e o município de Arraial do Cabo.

\subsection{O município de São José dos Campos}

O município paulista de São José dos Campos representa um exemplo típico de pólo tecnológico, responsável por congregar distintas empresas e institutos de pesquisa associados ao setor aeronáutico-aeroespacial.

Estudos pioneiros em prospecção tecnológica e utilização de novas técnicas foram realizados nos laboratórios isolados, montados no campus do Departamento de Ciência e Tecnologia Aeroespacial (CTA). O Instituto Tecnológico da Aeronáutica (ITA) e o CTA passaram a irradiar tecnologia, suportando a criação de diversas empresas, em sua maioria fundada por egressos daquele Instituto de Engenharia, das quais a de maior destaque seria a Empresa Brasileira de Aeronáutica S.A. (EMBRAER). Com o transcurso dos anos, os laboratórios sofreram complexas evoluções, em virtude da demanda e da aquisição de novos conhecimentos, originando os institutos atualmente existentes: o Instituto de Aeronáutica e Espaço (IAE), o Instituto de Estudos Avançados (IEAv) e o Instituto de Fomento e Coordenação Industrial (IFI) (FORJAZ, 2005).

O IFI é uma das organizações subordinadas ao CTA e presta serviços nas searas de normalização; metrologia, certificação de produto e de sistema; desenvolvimento industrial; 
mobilização industrial; e inovação tecnológica, a fim de contribuir para a garantia do desempenho, da segurança e da disponibilidade de produtos e serviços aeroespaciais, nos quais a Aeronáutica tenha interesse.

O IFI está localizado na cidade de São José dos Campos, distante aproximadamente 97 km de São Paulo-SP, 343 Km do Rio de Janeiro e 526 Km de Belo Horizonte.

No quadro 1, encontram-se resumidas as principais características demográficas e socioeconômicas do município de São José dos Campos, onde está localizado o IFI.

\begin{tabular}{|c|c|c|}
\hline Atributos & Valores & Observações \\
\hline População & 629.921 habitantes & $\begin{array}{l}\text { São José dos Campos é o } 7^{\circ} \text { município } \\
\text { mais populoso do estado de SP (IBGE, } \\
\text { 2012) }\end{array}$ \\
\hline Área da unidade territorial & $1.099,409 \mathrm{~km}^{2}$ & $\begin{array}{l}\text { Informação disponível no portal IBGE } \\
\text { Cidades }\end{array}$ \\
\hline Densidade demográfica & $572,77 \mathrm{hab} . / \mathrm{Km}^{2}$ & $\begin{array}{l}\text { Informação disponível no portal IBGE } \\
\text { Cidades }\end{array}$ \\
\hline PIB a preços correntes & $\mathrm{R} \$ 20.718 .595 .000$ & $\begin{array}{l}\text { O PIB representa a soma - em valores } \\
\text { monetários - de todos os bens e serviços } \\
\text { finais produzidos em uma determinada } \\
\text { região, em um certo período. O PIB de } \\
\text { São José dos Campos é o } 21^{\circ} \text { maior do } \\
\text { país e o } 8^{\circ} \text { maior do estado de São Paulo } \\
\text { (IBGE, 2008). }\end{array}$ \\
\hline Universidades & 06 & $\begin{array}{l}\text { Instituto Tecnológico da Aeronáutica } \\
\text { (ITA), UNIFESP, Universidade Estadual } \\
\text { Paulista "Júlio de Mesquita Filho" } \\
\text { (UNESP), Universidade do Vale do } \\
\text { Paraíba (UNIVAP), Universidade Paulista } \\
\text { (UNIP) e Fundação Armando Álvares } \\
\text { Penteado (FAAP) (Prefeitura Municipal } \\
\text { de São José dos Campos). }\end{array}$ \\
\hline Faculdades & 04 & $\begin{array}{l}\text { Faculdade de Tecnologia (FATEC), } \\
\text { Faculdades Anhanguera Educacional, } \\
\text { Faculdades ETEP e Instituto de Filosofia } \\
\text { Santa Terezinha (Prefeitura Municipal de } \\
\text { São José dos Campos). }\end{array}$ \\
\hline Índice de Gini & 0,41 & $\begin{array}{l}\text { É um instrumento empregado para aferir o } \\
\text { grau de concentração de renda em } \\
\text { determinado grupo, apontando a diferença } \\
\text { entre os rendimentos dos mais pobres e } \\
\text { dos mais ricos. Varia de zero a um: o } \\
\text { valor zero representa a situação de } \\
\text { igualdade e o valor um corresponde à } \\
\text { situação oposta - só uma pessoa concentra } \\
\text { toda a riqueza. O índice referente ao Brasil } \\
\text { é de } 0,576 \text { (PNUD, 2004; IBGE, 2003). }\end{array}$ \\
\hline IDH. & 0,849 (alto) & $\begin{array}{l}\text { O IDH representa uma medida } \\
\text { comparativa que contempla três variáveis: } \\
\text { riqueza, educação e expectativa de vida ao } \\
\text { nascer. São José dos Campos ocupa a } 37^{\mathrm{a}} \\
\text { posição no ranking nacional de IDH e a } \\
11^{\mathrm{a}} \text { posição no ranking do Estado de São } \\
\text { Paulo (PNUD, 2003). }\end{array}$ \\
\hline Ranking de Empregos & $\begin{array}{c}71^{a} \text { colocação em SP } \\
194^{a} \text { colocação no Brasil }\end{array}$ & $\begin{array}{l}\text { De acordo com o ranking FIRJAN de } \\
\text { emprego e renda, ano base } 2010 \text {, São José } \\
\text { dos Campos ocupa a } 71^{\mathrm{a}} \text { colocação no } \\
\text { ranking municipal de empregos do Estado } \\
\text { de SP e a 194 posição no ranking } \\
\text { nacional (FIRJAN, 2012). }\end{array}$ \\
\hline
\end{tabular}

Quadro 1: Características demográficas e socioeconômicas do Município de São José dos Campos

Fonte: Adaptado de FIRJAN (2012), IBGE (2012), IBGE (2008), IBGE (2003), PNUD (2003), PNUD (2004), 
Portal IBGE Cidades ${ }^{1}$, Portal da Prefeitura Municipal de São José dos Campos².

De acordo com os atributos demográficos e socioeconômicos da cidade de São José dos Campos, bem como os apontamentos realizados por Lima (1992), observa-se que o IFI está em um ambiente de inovação, delineado pelo polo tecnológico de São José dos Campos. Lima (1992, p.23) destaca que no parque tecnológico de São José dos Campos "a presença de alguns grandes grupos industriais, com determinada força política e militar" possibilita a existência de "um mando político, fundamental a sua sobrevivência e importância." Essa localização privilegiada do IFI poderá contribuir para a viabilização das atividades de pesquisa e desenvolvimento conduzidas naquele Instituto.

O ITA, organização militar de ensino e pesquisa também situada no complexo aeroespacial de São José dos Campos e igualmente subordinada ao CTA, abriga a incubadora aeroespacial "IncubAero".

A "IncubAero" ${ }^{3}$ foi inaugurada em 30 de novembro de 2004 e sua formalização se deu por meio da assinatura de um protocolo de intenções entre representantes do CTA, ITA, Fundação Casimiro Montenegro Filho (FCMF), Prefeitura Municipal de São José dos Campos, Centro das Indústrias do Estado de São Paulo (CIESP) e SEBRAE. A incubadora conta com uma área aproximada de $900 \mathrm{~m} 2$ e oferece uma reunião de condições que viabilizam o desenvolvimento e a conversão de ideias e projetos em novos produtos e/ou processos que possam atingir o mercado de forma eficiente. O seu principal objetivo é dar suporte ao empreendedorismo e ao desenvolvimento de tecnologias no setor aeroespacial, especialmente em micro e pequenas empresas de base tecnológica (FRANÇA, 2004).

\subsection{O município de Campinas}

Fernandes, Côrtes e Pinho (2004, p.170) observaram que há uma maior interação das empresas situadas nos municípios de Campinas e São Carlos com centros de pesquisa, em relação à média geral do estado de São Paulo. Os autores atribuem esse achado à presença de destacadas universidades e centros de pesquisa direcionados às áreas tecnológicas, contribuindo não somente para a interação, como a possível geração de um ambiente mais favorável à criação de novas empresas. Em Campinas, estão presentes instituições renomadas, tais como: o Instituto Agronômico de Campinas (IAC), a Coordenadoria de Assistência Técnica Integral (CATI), o Centro de Pesquisa e Desenvolvimento em Telecomunicações (CPqD), o Centro de Tecnologia da Informação Renato Archer (CTI) e a Universidade Estadual de Campinas (UNICAMP).

Para Fernandes, Côrtes e Pinho (2004, p.171), os progressos técnicos observados nas instituições estudadas podem traduzir a confirmação de que, ainda que se observe um ambiente macroeconômico indefinido, a tecnologia e a inovação conservam a crucialidade no que tange à competitividade, à capacidade de sondar oportunidades e à garantia da permanência no mercado.

$\mathrm{O} \mathrm{CPqD}$ atua nos setores produtivos que envolvem engenharia elétrica, ciência da computação, fornecimento de sistemas de software, prestação de serviços tecnológicos, licenciamento de tecnologias de produtos, prestação de serviços tecnológicos, de consultoria e laboratoriais, bem como a condução de projetos de P\&D de base tecnológica (PARADISI, 2012).

O CPqD está localizado na cidade de Campinas, distante aproximadamente $120 \mathrm{~km}$ de São Paulo-SP, $500 \mathrm{Km}$ do Rio de Janeiro e $580 \mathrm{Km}$ de Belo Horizonte. No quadro 2, encontram-se resumidas as principais características demográficas e socioeconômicas do município de Campinas.

\footnotetext{
${ }^{1}$ Portal IBGE Cidades. Disponível em: <www.ibge.gov.br/cidadesat/topwindow.htm?1> Acesso em 08 ago. 2013.

${ }^{2}$ Portal da Prefeitura Municipal de São José dos Campos. Disponível em: <www.sjc.sp.gov.br> Acesso em 08 ago. 2013.

${ }^{3}$ Mais informações sobre a Incubadora Aeroespacial "IncubAero" podem ser acessadas no sítio oficial da instituição na Internet: <www.incubaero.org.br>.
} 


\begin{tabular}{|c|c|c|}
\hline Atributos & Valores & Observações \\
\hline População & 1.080.113 habitantes & $\begin{array}{l}\text { Campinas é o } 3^{\circ} \text { município mais populoso do } \\
\text { estado de SP (IBGE, 2012) }\end{array}$ \\
\hline $\begin{array}{l}\text { Área da unidade } \\
\text { territorial }\end{array}$ & $795,004 \mathrm{Km}^{2}$ & Informação disponível no portal IBGE Cidades \\
\hline $\begin{array}{c}\text { Densidade } \\
\text { demográfica }\end{array}$ & $1.358,63 \mathrm{hab} / \mathrm{Km}^{2}$ & Informação disponível no portal IBGE Cidades \\
\hline PIB a preços correntes & $\mathrm{R} \$ 29.363 .064 .000$ & $\begin{array}{l}\text { O PIB representa a soma - em valores monetários - } \\
\text { de todos os bens e serviços finais produzidos em } \\
\text { uma determinada região, em certo período.O PIB } \\
\text { de Campinas é o } 13^{\circ} \text { maior do país e o } 5^{\circ} \text { maior do } \\
\text { estado de São Paulo (IBGE, 2008). }\end{array}$ \\
\hline Universidades & 06 & $\begin{array}{l}\text { UNICAMP, Pontifícia Universidade Católica de } \\
\text { Campinas (PUC-Campinas), UNIP e Universidade } \\
\text { São Francisco (USF) (Prefeitura Municipal de } \\
\text { Campinas). }\end{array}$ \\
\hline Faculdades & 12 & $\begin{array}{l}\text { Escola Superior de Administração, Marketing e } \\
\text { Comunicação (ESAMC), Escola Superior de } \\
\text { Propaganda e Marketing (ESPM), Faculdade e } \\
\text { Centro de Pesquisas Odontológicas São Leopoldo } \\
\text { Mandic (FCPOSLM), Faculdade Politécnica de } \\
\text { Campinas (POLICAMP), Veris Faculdades, } \\
\text { Faculdades Anhanguera Educacional, Faculdades } \\
\text { de Campinas (FACAMP), Faculdades Fleming, } \\
\text { Instituto de Educação e Escola Superior de } \\
\text { Campinas (IESCAMP), Instituto Paulista de Estudo } \\
\text { e Pesquisa (IPEP) e Centro Universitário Salesiano } \\
\text { de São Paulo (UNISAL) (Prefeitura Municipal de } \\
\text { Campinas). }\end{array}$ \\
\hline Índice de Gini ${ }^{4}$ & 0,42 & $\begin{array}{l}\text { É um instrumento empregado para aferir o grau de } \\
\text { concentração de renda em determinado grupo, } \\
\text { apontando a diferença entre os rendimentos dos } \\
\text { mais pobres e dos mais ricos. Varia de zero a um: o } \\
\text { valor zero representa a situação de igualdade e o } \\
\text { valor um corresponde à situação oposta - só uma } \\
\text { pessoa concentra toda a riqueza. O índice referente } \\
\text { ao Brasil é de } 0,576 \text { (PNUD, 2004; IBGE, 2003) }\end{array}$ \\
\hline IDH & 0,852 (alto) & $\begin{array}{l}\text { O IDH representa uma medida comparativa que } \\
\text { contempla três variáveis: riqueza, educação e } \\
\text { expectativa de vida ao nascer. Campinas ocupa a } \\
24^{\mathrm{a}} \text { posição no ranking nacional de IDH e a } 7^{\mathrm{a}} \\
\text { posição no ranking do Estado de São Paulo (PNUD, } \\
\text { 2003). }\end{array}$ \\
\hline Ranking de Empregos & $\begin{array}{l}16^{\mathrm{a}} \text { colocação em SP } \\
39^{\mathrm{a}} \text { colocação no Brasil }\end{array}$ & $\begin{array}{l}\text { De acordo com o ranking FIRJAN de emprego e } \\
\text { renda, ano base 2010, Campinas ocupa a } 16^{\mathrm{a}} \\
\text { colocação no ranking municipal de empregos do } \\
\text { Estado de SP e a } 39^{\mathrm{a}} \text { colocação no ranking nacional } \\
\text { (FIRJAN, 2012). }\end{array}$ \\
\hline
\end{tabular}

Quadro 2: Características demográficas e socioeconômicas do Município de Campinas

Fonte: Adaptado de FIRJAN (2012), IBGE (2012), IBGE (2008), IBGE (2003), PNUD (2003), PNUD (2004), Portal IBGE Cidades ${ }^{5}$, Portal da Prefeitura Municipal de Campinas ${ }^{6}$

Em função das características demográficas e socioeconômicas da Cidade de Campinas, bem como os apontamentos realizados por Steiner, Cassim e Robazzi (2008) e Fernandes, Côrtes e Pinho (2004), observa-se que o CPqD está inserido em um ambiente de

\footnotetext{
${ }^{5}$ Portal IBGE Cidades. Disponível em: <www.ibge.gov.br/cidadesat/topwindow.htm?1> Acesso em 08 ago. 2013.

${ }^{6}$ Portal da Prefeitura Municipal de Campinas. Disponível em: <www.campinas.sp.gov.br> Acesso em 08 ago. 2013
} 
inovação, materializado pelo polo tecnológico de Campinas, fato que poderá viabilizar as atividades de $\mathrm{P} \& \mathrm{D}$ realizadas naquele Instituto.

\subsection{O município de Arraial do Cabo}

O Instituto de Estudos do Mar Almirante Paulo Moreira (IEAPM) é uma instituição científica e tecnológica da Marinha do Brasil, a qual compete planejar e executar as atividades de pesquisa e desenvolvimento científico e tecnológico nas áreas de Oceanografia, Meteorologia, Hidrografia, Geologia e Geofísica Marinhas, Instrumentação Oceanográfica, Acústica Submarina e de Engenharia Costeira e Oceânica.

O IEAPM está localizado na cidade de Arraial do Cabo, distante aproximadamente $591 \mathrm{~km}$ de São Paulo-SP, $154 \mathrm{Km}$ do Rio de Janeiro e 579 Km de Belo Horizonte. No quadro 3 , encontram-se resumidas as principais características demográficas e socioeconômicas do município de Arraial do Cabo, onde está localizado o IEAPM.

\begin{tabular}{|c|c|c|}
\hline Atributos & Valores & Observações \\
\hline População & 27.715 habitantes & $\begin{array}{l}\text { Informação disponível no portal IBGE } \\
\text { Cidades }\end{array}$ \\
\hline Área da unidade territorial & $160,286 \mathrm{~km}^{2}$ & $\begin{array}{l}\text { Informação disponível no portal IBGE } \\
\text { Cidades }\end{array}$ \\
\hline Densidade demográfica & $172,91 \mathrm{hab} . / \mathrm{Km}^{2}$ & $\begin{array}{l}\text { Informação disponível no portal IBGE } \\
\text { Cidades }\end{array}$ \\
\hline PIB a preços correntes & $\mathrm{R} \$ 328.840 .250,00$ & $\begin{array}{l}\text { O PIB representa a soma - em valores } \\
\text { monetários - de todos os bens e serviços } \\
\text { finais produzidos em uma determinada } \\
\text { região, em um certo período. Arraial do } \\
\text { Cabo não está elencado no ranking dos } \\
100 \text { maiores municípios do país em } \\
\text { relação ao PIB a preços correntes } \\
\text { (IBGE, 2008). }\end{array}$ \\
\hline Universidades e Faculdades & $\begin{array}{c}\text { Não existem } \\
\text { Universidades e } \\
\text { Faculdades no Município }\end{array}$ & $\begin{array}{l}\text { Não existem Universidades } \\
\text { Faculdades em Arraial do Cabo. As } \\
\text { instituições de ensino superior mais } \\
\text { próximas estão situadas no município } \\
\text { de Cabo Frio, a uma distância } \\
\text { aproximada de } 13,5 \text { quilômetros. }\end{array}$ \\
\hline Índice de Gini & 0,39 & $\begin{array}{l}\text { É um instrumento empregado para } \\
\text { aferir o grau de concentração de renda } \\
\text { em determinado grupo, apontando a } \\
\text { diferença entre os rendimentos dos mais } \\
\text { pobres e dos mais ricos. Varia de zero a } \\
\text { um: o valor zero representa a situação } \\
\text { de igualdade e o valor um corresponde } \\
\text { à situação oposta - só uma pessoa } \\
\text { concentra toda a riqueza. O índice } \\
\text { referente ao Brasil é de } 0,576 \text { (PNUD, } \\
\text { 2004; IBGE, 2003). }\end{array}$ \\
\hline IDH. & 0,79 (médio) & $\begin{array}{l}\text { O IDH representa uma medida } \\
\text { comparativa que contempla três } \\
\text { variáveis: riqueza, educação } \\
\text { expectativa de vida ao nascer. Arraial } \\
\text { do Cabo ocupa a } 14^{\mathrm{a}} \text { posição no ranking } \\
\text { do Estado do Rio de Janeiro (PNUD, } \\
\text { 2003). }\end{array}$ \\
\hline Ranking de Empregos & $\begin{array}{c}13^{\mathrm{a}} \text { colocação no RJ } \\
219^{\mathrm{a}} \text { colocação no Brasil }\end{array}$ & $\begin{array}{l}\text { De acordo com o ranking Federação } \\
\text { das Indústrias do Rio de Janeiro } \\
\text { (FIRJAN) de emprego e renda, ano } \\
\text { base 2010, Arraial do Cabo ocupa a } 13^{\text {a }} \\
\text { colocação no ranking municipal de }\end{array}$ \\
\hline
\end{tabular}




\begin{tabular}{|l|l|}
\hline & $\begin{array}{l}\text { empregos do Estado do RJ e a 219 } \\
\text { posição no ranking nacional (FIRJAN, } \\
\text { 2012). }\end{array}$ \\
\hline
\end{tabular}

Quadro 3 : Características demográficas e socioeconômicas do Município de Arraial do Cabo

Fonte: Adaptado de FIRJAN (2012), IBGE (2012), IBGE (2008), IBGE (2003), PNUD (2003), PNUD (2004), Portal IBGE Cidades ${ }^{7}$ e Portal da Prefeitura Municipal de Arraial do Cabo ${ }^{8}$.

O IEAPM, por meio do seu Museu Oceanográfico, participa do Programa de Mentalidade Marítima, estabelecido em 1998 pela Comissão Interministerial para os Recursos do Mar. O objetivo desse programa é estimular na sociedade a percepção do valor do mar e do cultivo de hábitos, atitudes e comportamentos que assegurem o conhecimento das potencialidades do mar e o aproveitamento racional desse ambiente. $\mathrm{O}$ trabalho foi iniciado com a aplicação de questionário de opinião pública, objetivando estabelecer o índice de mentalidade marítima e a aceitação do programa na região de Arraial do Cabo, Cabo Frio e São Pedro da Aldeia. Os resultados indicaram "bom índice e uma ótima aceitação do programa", contudo, apontou para a necessidade da implementação de minicursos préprofissionalizantes que incrementassem a capacitação das comunidades carentes, fomentando a mentalidade marítima e propalando a atuação da MB (INSTITUTO DE ESTUDOS DO MAR ALMIRANTE PAULO MOREIRA, 2003b).

O Projeto Oficinas do Mar consiste de três minicursos nas áreas de Construção Naval Básica, Artesão do Mar e Guia Oceanográfico, com um público alvo majoritariamente formado por jovens dos municípios de Arraial do Cabo, Cabo Frio e São Pedro da Aldeia. Além do viés conscientizador acerca da utilização racional do meio-ambiente natural e humano, as aulas têm um caráter pré-profissionalizante, estimulando o desenvolvimento de aptidões nas áreas de carpintaria, artesanato e turismo (INSTITUTO DE ESTUDOS DO MAR ALMIRANTE PAULO MOREIRA, 2003a).

Em última análise, existe a previsão de que aquele Instituto sedie um dos quatro Institutos Nacionais de Ciência e Tecnologia de Ciências do Mar a serem criados, como fruto de recomendações emanadas por ocasião da a $4^{\text {a }}$ Conferência Nacional de Ciência e Tecnologia, de 2010. Será o único localizado em território fluminense; os demais estarão sediados em São Paulo-SP, Rio Grande-RS e Salvador-BA (INSTITUTO DE ESTUDOS DO MAR ALMIRANTE PAULO MOREIRA, 2011).

\section{CONSIDERAÇÕES FINAIS}

O presente artigo assumiu como tema a análise dos papéis desempenhados pelos atores governo, universidade, empresa e instituição científica e tecnológica em municípios localizados em território paulista e fluminense.

No que tange ao primeiro problema de pesquisa - "como estão dispostos os atores nos municípios analisados?" -, observa-se que governo, universidade e empresa assumem disposições distintas em cada um dos municípios em estudo. Em São José dos Campos e Campinas, identifica-se um ambiente sinérgico sob a ótica da inovação, o que pode ser corroborado pelas informações referentes ao quantitativo de universidades públicas e particulares, bem como pela representatividade das instituições científicas e tecnológicas instaladas naqueles municípios. Já em relação ao município de Arraial do Cabo, constata-se que as atividades de pesquisa e desenvolvimento são irradiadas a partir do Instituto de Estudos do Mar Almirante Paulo Moreira (IEAPM), que, a partir de 2014, sediará Programa de Pós-Graduação em Ciências do Mar. Trata-se de iniciativa que poderá suprir parcialmente a carência de universidades e faculdades naquele município fluminense, especificamente instituições de ensino superior integrantes de grupos de pesquisa na seara de ciências do mar.

\footnotetext{
${ }^{7}$ Portal IBGE Cidades. Disponível em: <www.ibge.gov.br/cidadesat/topwindow.htm?1> Acesso em 08 ago. 2013.

${ }^{8}$ Portal da Prefeitura Municipal de Arraial do Cabo. Disponível em: <www.arraial.rj.gov.br> Acesso em 08 ago. 2013.
} 
Em relação ao segundo problema de pesquisa -"as características demográficas e socioeconômicas dos municípios estudados propiciam o desenvolvimento de ambientes de inovação?" -, vislumbra-se que as características atinentes aos índices de Gini e de desenvolvimento humano; ao ranking de empregos; e à representatividade das instituições científicas e tecnológicas instaladas em São José de Campos e Campinas apontam para a conformação de ambientes de inovação e polos tecnológicos naquelas localidades, o que não pode ser identificado em Arraial do Cabo.

Acerca do terceiro problema de pesquisa - "quais são as contribuições fornecidas pelos atores envolvidos ao desenvolvimento de ambientes de inovação nos municípios analisados?"-, conclui-se que, em São José dos Campos e Campinas, universidade, empresa e governo oferecem robustas contribuições ao desenvolvimento de ambientes de inovação. Em São José dos Campos, os seguintes atores merecem destaque: Departamento de Ciência e Tecnologia Aeroespacial (DCTA) e institutos de pesquisa vinculados; Instituto Tecnológico da Aeronáutica (ITA); universidades públicas e privadas; órgãos governamentais; e agências de fomento. No município de Campinas, as ações são empreendidas de modo semelhante, especialmente pela atuação relevante dos seguintes agentes: UNICAMP e demais universidades públicas e privadas; $\mathrm{CPqD}$ e demais centros de pesquisa; órgãos governamentais; e agências de fomento.

Em Arraial do Cabo, observa-se que o IEAPM tem atuação destacada, contribuindo especialmente pelo preenchimento parcial do hiato proveniente da ausência de universidades e faculdades naquele município e da atuação incipiente da administração pública além dos limites daquela instituição militar de pesquisa, quando realizada comparação com os municípios paulistas de São José dos Campos e Campinas.

No que concerne ao quarto e último problema de pesquisa - "como poderiam ser classificados os distritos industriais nos quais estão situadas as unidades de análise da pesquisa?" - identifica-se que as unidades de análise estão situadas preponderantemente em distritos industriais suportados pelo Estado, especialmente pela relevância dos complexos militares e das instituições públicas de pesquisa neles situados, embora as peculiaridades de São José dos Campos e Campinas aproximem aquelas cidades de distritos industriais de classificação centro-radial.

Este estudo apresenta limitações associadas ao fato de o resultado da pesquisa estar adstrito exclusivamente aos três casos estudados, sendo impossível a sua generalização, o que demandaria acompanhamento e avaliação das especificidades existentes.

Em última análise, sugere-se a título de pesquisa futura o aprofundamento do estudo dos elementos constitutivos das políticas organizacionais de ciência, tecnologia e inovação e de gestão de ativos intangíveis em instituições científicas e tecnológicas sediadas em unidades da federação localizadas nas demais regiões brasileiras.

\section{REFERÊNCIAS}

AMARAL, R. Texto revisto da Palestra "Ciência e Tecnologia, defesa e soberania para a construção de um Projeto Nacional", proferida durante a "Sexta Rodada de Debates sobre o 'Pensamento brasileiro sobre Segurança e Defesa', promovida pelo Ministério da Defesa em Petrópolis-RJ, no Centro General Ernani Ayrosa, em 3 e 4 de abril de 2004. In: AMARAL, R. Ciência, tecnologia e soberania nacional: dificuldades para a construção de um projeto nacional. Brasília, DF: Senado Federal, 2011.

ANDRADE, T. N. de. Aspectos Sociais e Tecnológicos das Atividades de Inovação. Lua Nova, São Paulo, $\mathrm{n}^{\mathrm{o}}$ 66, p.139-166, 2006. Disponível em: <http://www.scielo.br/pdf/ln/n66/29087.pdf> Acesso em: 08 ago. 2013. 
CASSIOLATO, J. E.; LASTRES, H. M. M.. Sistemas de inovação e desenvolvimento: as implicações de política. São Paulo Perspec. [online]. 2005, vol.19, n.1, pp. 34-45. ISSN 0102-8839. Disponível em: 〈http://www.scielo.br/pdf/spp/v19n1/v19n1a03.pdf > Acesso em 08 ago. 2013.

CRUZ JUNIOR, A. S. Diplomacia, desenvolvimento e sistemas nacionais de inovação: estudo comparado entre Brasil, China e Reino Unido. Brasília, DF: Fundação Alexandre de Gusmão, 2011, v. 1, 292p .

EUROPEAN COMMISSION. The Structural Funds and their coordination with the Cohesion Fund: guidelines for programmes in the period 2000-2006. European Union, Regional Policy, 1999b.

Network of Innovation Regions in Europe - Good Pratices on Regional Innovation and Technology Transfer Strategies and Infrastructures - RITTS, Regional Innovation Strategy - RIS and Regional Technology Plan - RTP, Pilot Projects across Europe, 1999a.

FERNANDES, A. C.; CÔRTES, M. R.; PINHO, M.. Caracterização das pequenas e médias empresas de base tecnológica em São Paulo: uma análise preliminar. Economia e Sociedade, Campinas, v. 13, n. 1 (22), p. 151-173, jan./jun. 2004. Disponível em: < www.eco.unicamp.br/docdownload/publicacoes/instituto/revistas/economia-e-sociedade/V13F1-S22/FernandesCortesPinho.pdf> Acesso em 08 ago. 2013.

FEDERAÇÃO DAS INDÚSTRIAS DO ESTADO DO RIO DE JANEIRO. Índice FIRJAN de desenvolvimento municipal. Edição 2012 - ano base 2010, 2012. Disponível em: <www.firjan.org.br/ifdm/consulta-ao-indice/> Acesso em 08 ago. 2013.

FORJAZ, M. C. S.. As origens da Embraer. Tempo Soc. [online]. 2005, vol.17, n.1, pp. 281 298. Disponível em: <www.scielo.br/pdf/ts/v17n1/v17n1a11.pdf> Acesso em 08 ago. 2013.

FRANÇA, R.. Inaugurada, no campus Montenegro, a incubadora aeroespacial "IncubAero". Assessoria de Imprensa do ITA, 30 nov. 2004. Disponível em: <http://www.ita.br/online/2004/noticias04/incubaeroinaug.htm> Acesso em 08 ago. 2013.

GIL, A. C. Como elaborar projetos de pesquisa. 5. ed. São Paulo: Atlas, 2010.

INSTITUTO BRASILEIRO DE GEOGRAFIA E ESTATÍSTICA (Brasil). Censo Demográfico 2010, 2012. Disponível em: 〈http://www.censo2010.ibge.gov.br>. Acesso em 08 ago. 2013.

Pesquisa de Orçamentos Familiares 2002-2003, 2003. Disponível em: <http://www.ibge.gov.br/home/estatistica/populacao/condicaodevida/pof/2002/pof2002.pdf> Acesso em 08 ago. 2013.

Produto Interno Bruto dos Municípios 2004-2008, 2008. Disponível em: <http://www.ibge.gov.br/home/estatistica/economia/pibmunicipios/2004_2008/default.shtm> Acesso em 08 ago. 2013.

INSTITUTO DE ESTUDOS DO MAR ALMIRANTE PAULO MOREIRA (Brasil). IEAPM será sede do Instituto Nacional de Ciência e Tecnologia (INCT). Informativo IEAPM, Arraial do Cabo, v. 1, n. 9, p. 1-4, 2011. 
2003a.

O Projeto Oficinas do Mar. A Ressurgência, Arraial do Cabo, v. 1, n. 1, p. 42,

Programa de mentalidade marítima: o museu oceanográfico. A Ressurgência,

Arraial do Cabo, v. 1, n. 1, p. 41, 2003b.

KIM, L. Imitation to Innovation: the dynamics of Korea's Technological Learning. Boston: Harvard Business School Press, 1997.

LIMA, L. C.. Tecnopólo: uma Forma de produzir na modernidade atual. Terra Livre, São Paulo, n.9, p. 19-40, 1992. Disponível em: <www.agb.org.br/files/TL_N9.pdf\#page=20>. Acesso em 08 ago. 2013.

LUNDVALL, B. National Systems of Innovation. Towards a theory of innovation and interactive learning. Londres: Pinter Publishers, 1992.

MACIEL, M. L.. Hélices, sistemas, ambientes e modelos: os desafios à Sociologia da Inovação. Sociologias, Porto Alegre, ano 3, $\mathrm{n}^{\mathrm{o}}$ 6, jul-dez, 2001, p. 18-29. Disponível em: <http://www.scielo.br/pdf/soc/n6/a02n6.pdf>. Acesso em 14 nov. 2012.

MACIEL, M. L.; BAUMGARTEN, M. Estímulos e desestímulos à divulgação do conhecimento científico. Conhecimentos e redes-sociedade, política e inovação. Porto Alegre: Ed. Universidade/UFRGS, 2005.

MARKUSEN, Ann. Áreas de atração de investimentos em um espaço econômico cambiante: uma tipologia de distritos industriais. Nova Economia. Belo Horizonte, v.5, n.2, dez.1995.

NELSON, R. R. National innovation systems: a comparative analysis. New York: Oxford University Press, 1993.

PARADISI, Alberto. Entrevista concedida ao autor pelo Diretor de Gestão da Inovação da Fundação CPqD. Campinas, São Paulo, 23 de outubro de 2012.

PROGRAMA DAS NAÇÕES UNIDAS PARA O DESENVOLVIMENTO. Atlas do desenvolvimento humano no Brasil de 2003: ranking do IDH Municipal (IDH-M) dos municípios do Brasil 2003, obtido com base no Censo 2000, 2003. Disponível em: $<\mathrm{http}$ ///www.pnud.org.br/atlas/ranking/IDH_Municipios_Brasil_2000.aspx ?indiceAccordion= 1\&li=li_Ranking2003>. Acesso em 08 ago. 2013

Relatório de Desenvolvimento Humano Global 2004: Liberdade Cultural num Mundo Diversificado, 2004. Disponível em: <http://www.pnud.org.br/hdr/arquivos/RDH2004/arqui1089900676.zip>. Acesso em 08 ago. 2013.

RODRIGUES, A. de J..Metodologia Científica, São Paulo: Avercamp, 2006.

STEINER, J. E.; CASSIM, M. B.; ROBAZZI, A. C.. Parques Tecnológicos: Ambientes de Inovação. Revista IEA. USP. São Paulo, 2008. Disponível em <http://www.iea.usp.br/iea/textos/steinercassimrobazziparquestec.pdf>. Acesso em 08 ago. 2013. 
TERRA, B. R. C. et al. Os contextos norte-americano e brasileiro de C\&T. In: ENCONTRO ANUAL DA ASSOCIAÇÃO NACIONAL DOS PROGRAMAS DE PÓS-GRADUAÇÃO EM ADMINISTRAÇÃO, 22., 2000, São Paulo. Anais... São Paulo: ANPAD, 2000.

TERRA, B. R. C. et al. Os contextos norte-americano e brasileiro de C\&T. In: ENCONTRO ANUAL DA ASSOCIAÇÃO NACIONAL DOS PROGRAMAS DE PÓS-GRADUAÇÃO EM ADMINISTRAÇÃO, 22., 2000, São Paulo. Anais... São Paulo: ANPAD, 2000.

TERRA, B. R. C.; BARROS, F. C. P.; SEIDL, P. R. Regional Innovation Systems: The case of Rio de Janeiro State. The Tenth International Conference on Management of Technology. IAMOT 2001, 19-22 march, Switzerland, p. 085b, 2001a.

UTTERBACK, J. M. Mastering the dynamics of innovation. Cambridge: Harvard University School Press, 1994.

YIN, R. K. Estudo de caso: planejamento e métodos. 4. ed. Porto Alegre: Bookman, 2010. 248p. 